\title{
EXPERIMENTAL INVESTIGATION OF MICRO-REINFORCED, ALKALI-ACTIVATED GROUND GRANULATED BLAST FURNACE SLAG WITH WOLLASTONITE
}

\author{
Ashley Waldron ${ }^{1}$, Benjamin Varela $^{2}$ \\ ${ }^{I}$ Department of Mechanical Engineering, Rochester Institute of Technology, Rochester, NY \\ ${ }^{2}$ Department of Mechanical Engineering, Rochester Institute of Technology, Rochester, NY
}

\begin{abstract}
The alkali activation of ground granulated blast furnace slag with a potassium-based solution has demonstrated production of a cementating material with early compressive strength higher than concretes based on ordinary Portland cement. This strength can be increased by reinforcing the paste with wollastonite micro-fibers. This paper presents the results obtained when an alkaliactivated slag paste was reinforced with two types of wollastonite, NYAD $G$ and wollastocoat. Compressive strength, setting time, and microscopic structure were analyzed as a function of type of wollastonite and percentage of wollastonite added. All properties were compared to potassium-based alkali-activated slag without wollastonite. Based on a 28 day compressive strength curve, it was determined that the optimal loading of wollastonite in slag generated an average compressive strength of 55.1 MPa, an increase in strength of $60 \%$ from the wollastonite-free sample. Higher loading of wollastonite was shown to significantly reduce the setting time of the samples.
\end{abstract}

The cost of all samples was compared to concrete based on ordinary Portland cement using average prices in western New York. It was found that the cost of AAS is about 6.4 times higher than regular concrete, for this reason alternative uses for microreinforced samples were explored.

Keywords: Wollastonite micro-fibers, ground granulated blast furnace slag, alkali-activation, reinforcement

\section{INTRODUCTION}

During the past decade there has been an important movement towards the development of green and sustainable construction materials. In the United States, the federal government has issued directives requiring federal sponsored construction projects to meet goals that promote sustainability and reduce greenhouse gas release. As the public becomes more concerned about the environmental impact of construction projects, they have started demanding more green products and more energy efficient buildings.

The production of Portland cement is critical for the development of any country. In the United States approximately 66 million metric tons of Portland cement was produced in 2011, worth approximately 6.6 billion dollars (Van Oss 2012). It has been reported in literature that the production of 1 ton of Portland cement releases approximately 1 ton of carbon dioxide emissions (Harditjo $\&$ Rangan 2005). The partial substitution of Portland cement with industrial byproducts is a technique currently being practiced in many projects (EPA 2009). However, it would be desirable to achieve the minimum utilization of Portland cement possible.

Geopolymerization (Davidovits, 1991) or alkali-activation (Duxson, Fernandez \& Provis 2007), as some authors prefer to call it, is an emerging technology with the potential to mitigate some of the unfavorable effects of Portland cement and satisfy the needs of this new market.

In these experiments, ground granulated blast furnace slag will be alkali-activated. In an attempt to improve material properties of alkali-activated slag (AAS), wollastonite micro-fibers (NYCO Minerals) will be introduced. The combination of physical properties and morphology make wollastonite microfibers an important material in applications where enhanced durability and strength are required. Particularly in concrete, wollastonite microfibers have proven to increase compressive and tensile strengths, reduce shrinkage and crazing, and increase durability during freeze-thaw cycles. Previous work by Silva and Thaumaturgo 2002 showed that wollastonite improves the fracture toughness of alkali activated materials.

\section{EXPERIMENTAL}

\subsection{Sample Preparation Procedure}

St. Mary's Ground Granulated Blast Furnace Slag (GGBFS) from Ontario, Canada with a Blaine fineness of $660 \mathrm{~kg} / \mathrm{m}^{2}$ and chemical composition of $38.3 \% \mathrm{CaO}, 37 \% \mathrm{SiO}_{2}, 8 \%$ $\mathrm{Al}_{2} \mathrm{O}_{3}, 10.5 \% \mathrm{MgO}, .43 \% \mathrm{~K}_{2} \mathrm{O}, .25 \% \mathrm{Na}_{2} \mathrm{O}$, and $1.7 \% \mathrm{SO}_{3}$ was used in all experiments. 
All samples used a potassium based activator. Previous experiments showed that potassium activators reduce the formation of efflorescence in AAS. The activating solution had molar ratios of $\mathrm{SiO}_{2} / \mathrm{K}_{2} \mathrm{O}=1$ and $\mathrm{H}_{2} \mathrm{O} / \mathrm{K}_{2} \mathrm{O}=10$. These ratios were selected based on previous experiments. The activator was prepared by dissolving amorphous silica (Aerosil 300, Evonic Industries) in a $45 \% \mathrm{KOH}$ solution (Brainerd Chemical Company). Once the appropriate amounts were mixed, the solution was left to rest for 24 hours before being used.

The mass ratio of GGBFS/activating solution was 2. All solid components were thoroughly mixed before activation to achieve a uniform distribution. Once the solution and dry components were mixed, the paste was cast in cylindrical molds. The molds were then left to sit at room temperature for one hour before being cured in a convection oven.

During this period of solidification, a separate sample was tested for setting time using a Vicat needle. After curing the samples were left at room temperature and tested for compressive strength at 1,7 , and 28 days using a Tinius Olsen universal testing machine. A minimum of 4 samples were tested for each mix.

In the first set of experiments, wollastonite (NYAD G) with a chemical composition of $46.15 \% \mathrm{CaO}, 51.6 \% \mathrm{SiO}_{2}, 0.77 \%$ $\mathrm{Fe}_{2} \mathrm{O}_{3}, 0.34 \% \quad \mathrm{Al}_{2} \mathrm{O}_{3}, 0.16 \% \mathrm{MnO}, 0.38 \% \mathrm{MgO}, 0.05 \%$ $\mathrm{TiO}_{2}$, and $0.05 \% \mathrm{~K}_{2} \mathrm{O}$ was added to the GGBFS in quantities of $10 \%, 15 \%, 20 \%$ and $30 \%$ per mass of slag and activated as described above. All samples were cured at $85{ }^{\circ} \mathrm{C}$ for 12 hours.

In the second set of experiments, wollastocoat, a polymercoated wollastonite, with chemical composition of $46.36 \%$ $\mathrm{CaO}, 51.6 \% \mathrm{SiO}_{2}, 0.77 \% \mathrm{Fe}_{2} \mathrm{O}_{3}, 0.4 \% \mathrm{Al}_{2} \mathrm{O}_{3}, 0.15 \% \mathrm{MnO}$, $0.15 \% \mathrm{MgO}, 0.05 \% \mathrm{TiO}_{2}$, and $0.02 \% \mathrm{~K}_{2} \mathrm{O}$ was used instead of NYAD $\mathrm{G}$ with the same quantity increments. The same procedure was followed as described in the previous experiments.

In the last set of experiments, only the GGBFS was activated as described previously. One sample set was cured at room temperature and another one was cured at $85^{\circ} \mathrm{C}$ for 12 hours, after which it was left at room temperature. The temperature of the reactions was obtained using thermochron ibuttons embedded in the samples. The size of each sample was 1 quart. For both cases, the temperature was recorded for one week.

\subsection{Characterization}

Scanning electron micrographs were taken for samples with $30 \%$ NYAD G and wollastocoat using a Jeol Electron Probe Microanalizer.

A TA Instruments DSC 2010 Differential Scanning Calorimeter (DSC) with Copper pans was used to identify the reactions during the curing of the alkali-activated GGBFS.

\section{RESULTS AND DISCUSSION}

\subsection{Setting Time}

The sample with $0 \%$ wollastonite starts to set in approximately 30 minutes and becomes fully rigid in approximately 40 minutes. As the amount of NYAD G was increased from $10 \%$ to $20 \%$ per mass, the setting times in all curves was shifted to the left by approximately 6 minutes. The shift was larger for the $30 \%$ loading, approximately 15 minutes, which means that at this loading, the setting time was reduced by approximately $50 \%$ (Figure 1a)

When wollastocoat was added in the same mass percentages, a similar trend was observed. In the $10 \%$ to $20 \%$ loading range the setting time was shifted to the left by approximately 5 minutes, but at the $30 \%$ loading, the shift was approximately 10 minutes. This means that the setting time when $30 \%$ of wollastocoat was added was reduced by $30 \%$ (Figure 1b).

The desired outcome of adding wollastocoat in small quantities was that it would prolong the setting time as seen in previous experiments. These results suggest that this would be true if both types of wollastonite had similar physical properties. Based on manufacturer's specifications, NYAD G has a loose density of $0.40 \mathrm{~g} / \mathrm{cm}^{3}$ with a median particle size of $55 \mu \mathrm{m}$ while wollastocoat has a loose density of $0.80 \mathrm{~g} / \mathrm{cm}^{3}$ with a median particle size of $50 \mu \mathrm{m}$. This means that for the same mass loading, $50 \%$ less per volume of wollastocoat was used. This might explain why the retarding effect of wollastocoat starts to be seen at $30 \%$ loading.

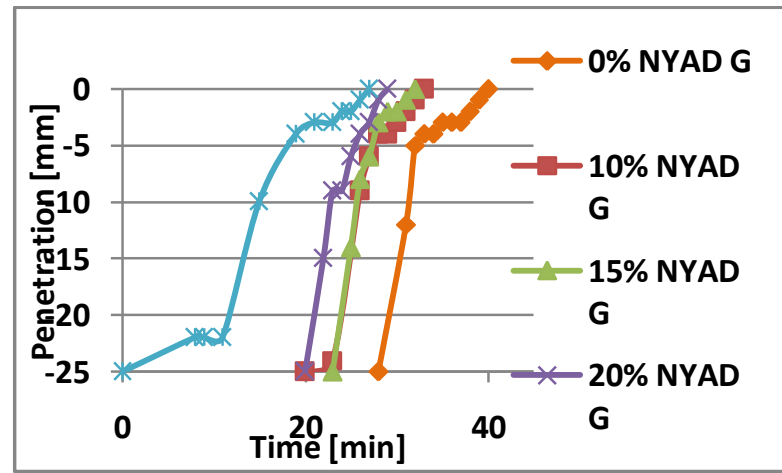

Fig 1a Setting time plots for NYAD G Samples

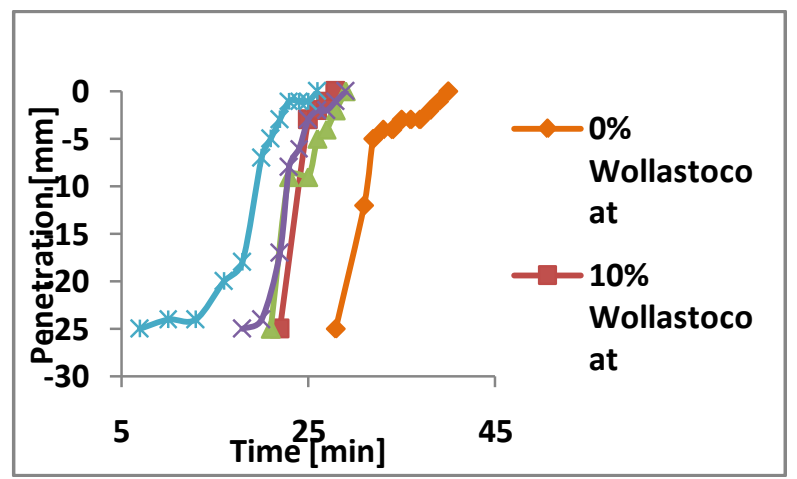

Fig 1b Setting time plots for wollastocoat Samples 


\subsection{Compressive Strength}

Figure 2A presents the results of compressive strength for samples with NYAD G. The samples with $0 \%$ NYAD G had an average compressive strength of $48.2 \mathrm{MPa}$ in 1 day, which remained stable for the first 7 days, but declined to $34.4 \mathrm{MPa}$ in 28 days, which represents a loss of approximately $30 \%$. When NYAD G was added, the 1 day average compressive strength reached $75.3 \mathrm{MPa}$ at $20 \%$ loading, but it lost approximately $26 \%$ over 28 days. The only formulation that remained fairly stable over the period of study was the 15\% NYAD G sample which had an average compressive strength of approximately 55.1 MPa. No correlation between the compressive strength and the loading of NYAD G was observed during the 1 and 7 day tests. The correlation became evident at the 28 day test when the compressive strength increased as the amount of NYAD $\mathrm{G}$ increased.

However, from Figure $2 \mathrm{a}$ it can be seen that the increase in strength is not directly proportional to the increase of NYAD G. The addition of $15 \%$ of NYAD G increased the compressive strength by $53 \%$ but by increasing the loading from $15 \%$ to $30 \%$ only increased the compressive strength by $10 \%$.

A similar trend was observed when wollastocoat was added. The maximum observed compressive strength was 75.8 $\mathrm{MPa}$ in 1 day at a $30 \%$ loading. As seen in Figure 2b, the loss of compressive strength during the first 7 days was more conspicuous for the $20 \%$ and $30 \%$ loadings. This represents a loss of approximately 30\%. After 7 days, the samples continue to lose strength, except for $20 \%$ and $30 \%$ loadings which remained stable at approximately 55.1 MPa.

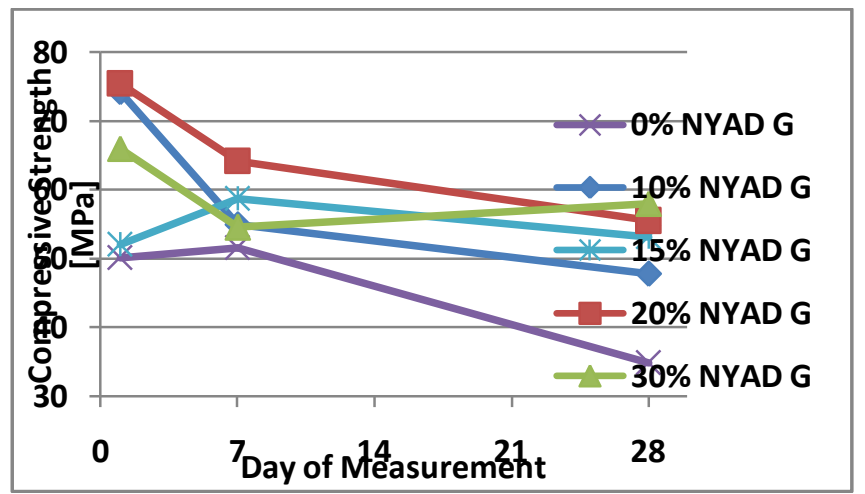

Fig 2a: Compressive strength for NYAD G Samples

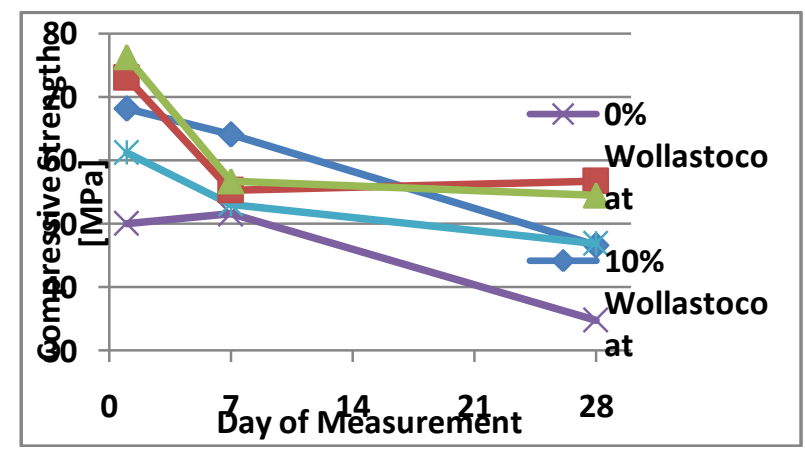

Fig 2b Compressive strength for Wollastocoat Samples

\subsection{Exploration of Curing Methods}

All these experiments suggested a relationship between curing temperature, early compressive strength, and strength retention. To investigate these effects, samples with no wollastonite were prepared and cured at room temperature. Figure 3 presents the compressive strength results of this experiment. As seen in this figure, curing at room temperature yielded a lower compressive strength, as compared to similar samples cured at $85^{\circ} \mathrm{C}$. The 1 day compressive strength was approximately $34.4 \mathrm{MPa}$, but it increased to $44.8 \mathrm{MPa}$ and remained stable after that.

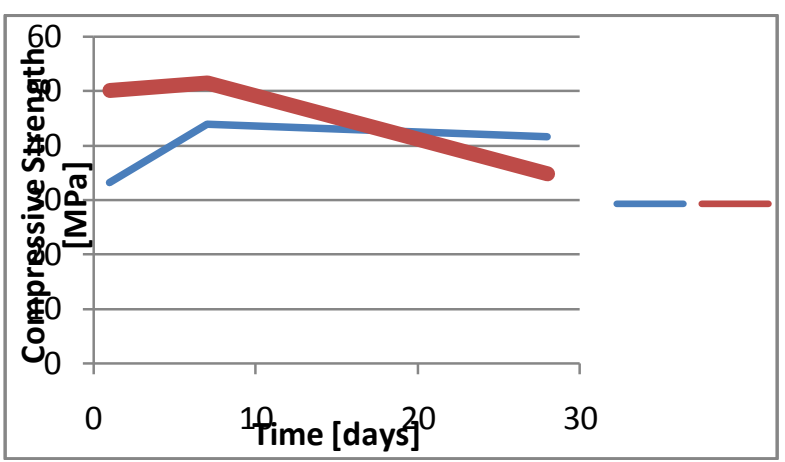

Fig 3 Comparison of Curing Methods

\subsection{Scanning Electron Microscopy}

Figure 4 presents the microstructural features of AAS observed by Scanning Electron Microscopy at 200X magnification. A dense microstructure with a rough surface, large cracks, and pores can be observed. This microstructure appears to be composed of two different phases, a dark matrix with a coagulated white phase on its surface.

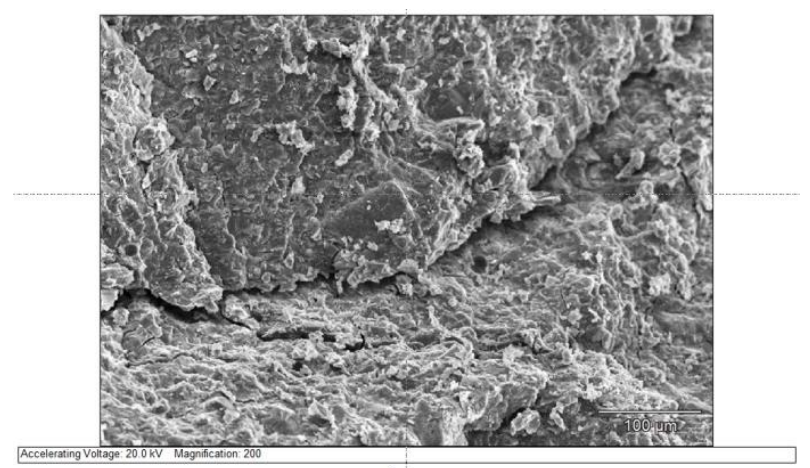

Fig 4 Scanning Electron Micrographs of 0\% NYAD G at 200X Magnification

Figures 5 and 6 present the morphology of the microstructure for samples with $30 \%$ NYAD G and wollastocoat respectively. In both cases micro cracks and pores were observed, but one can see how the acicular shape of the Wollastonite is embedded in the matrix. The previously observed white phase also tends to coagulate on the surface of the wollastonite. This observation implies a surface reaction among the wollastonite and the phases formed during alkali activation. It can also be seen how the wollastonite joins the gaps due to micro-cracks and pores. 

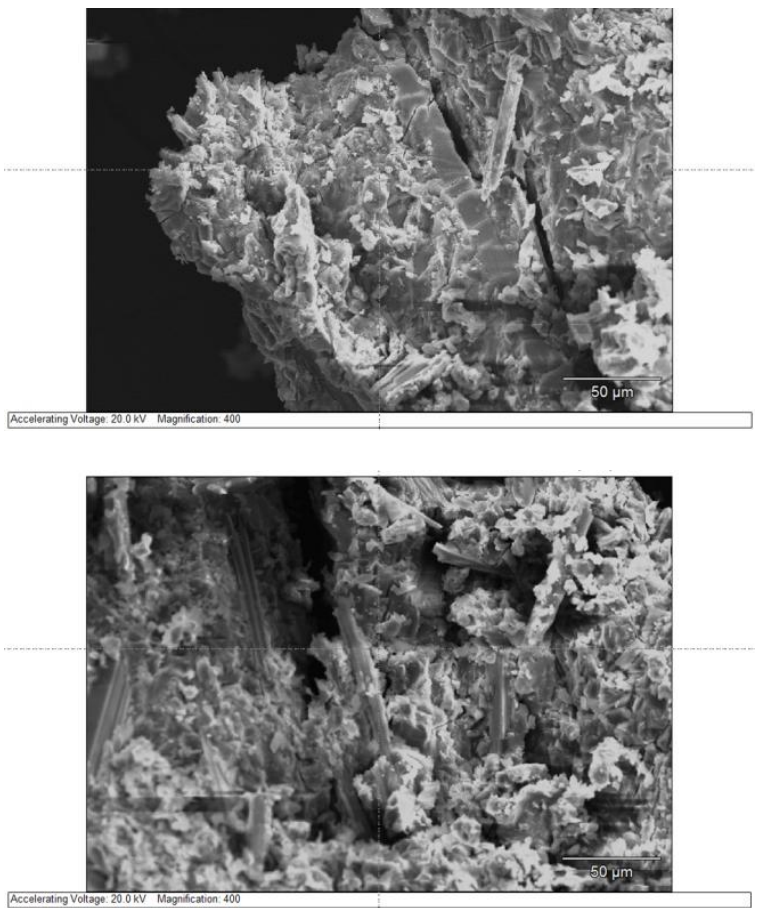

Fig 5 Scanning Electron Micrographs of 30\% NYAD G at 400X Magnification
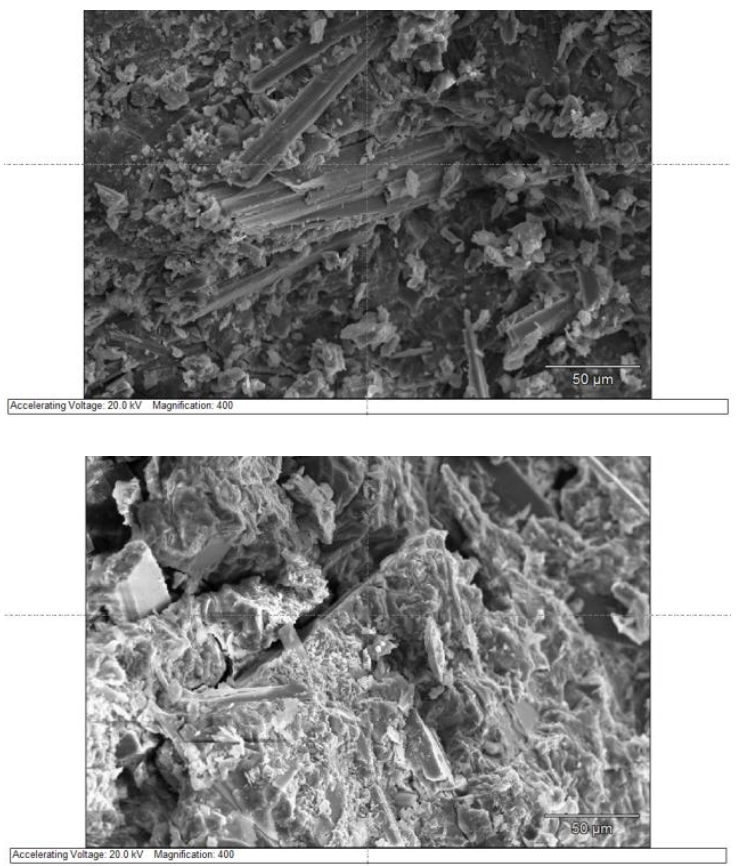

Fig 6 Scanning Electron Micrographs of $30 \%$ wollastocoat at 400X Magnification

\subsection{Temperature Evolution inside the Samples}

Figure 7 presents the temperature evolution inside the samples under isothermal conditions for the first 12 hours after mixture. In the first case (thick line), GGBFS was mixed with water at a 1:2 mass proportion and cured at room temperature. The hydration reaction evolves slowly, reaching a plateau at approximately 10 hours with a maximum temperature of approximately $30{ }^{\circ} \mathrm{C}$. The paste solidified after 24 hours but it showed no significant strength.
In the second experiment (medium-thick line), the same mass ratio was kept but the alkali activator was used instead of water. The reaction proceeded much faster reaching a peak of $94^{\circ} \mathrm{C}$ in approximately 3 hours. In the last experiment (thin line), the same composition was used but it was cured at $85^{\circ} \mathrm{C}$ and the reaction proceeds even faster reaching a peak of $111^{\circ} \mathrm{C}$ in approximately 1.5 hours. These experiments indicate that the curing temperature of $85^{\circ} \mathrm{C}$ is not optimal for these materials because it can cause rapid water evaporation which might be the cause of some of the cracks observed after curing.

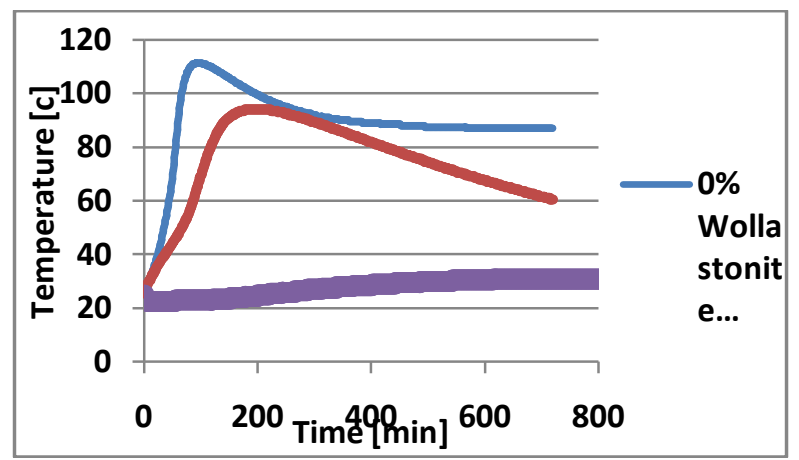

Fig 7 Temperature Evolution of Different Curing Methods

\subsection{Differential Scanning Calorimetry Experiments}

Figure $8 \mathrm{a}$ presents the heat flow from a wollastonite- free sample during the first DSC experiment, in which the sample was held isothermally at $25^{\circ} \mathrm{C}$ for 12 hours. A broad exothermic peak was observed starting at 20 minutes. No further reactions were observed after this peak and the heat signal reached a plateau at approximately 250 minutes, indicating that the curing process ended. This time range is in agreement with the setting times observed in the samples with $0 \%$ wollastonite.

In the second DSC experiment, the sample was ramped up to $85^{\circ} \mathrm{C}$ at a rate of $10^{\circ} \mathrm{C} / \mathrm{min}$. The signal reached a plateau at 75 minutes, but a clear exothermic peak was detected at approximately 400 minutes, this peak can be seen in Figure 8 b.

In the last DSC experiment, the sample was flash frozen in liquid Nitrogen immediately after the activation. The sample was held at $-20^{\circ} \mathrm{C}$ and then it was ramped up to $65^{\circ} \mathrm{C}$ at a rate of $10^{\circ} \mathrm{C} / \mathrm{min}$ and held isothermally for 10 hours. Figure $8 \mathrm{c}$ presents the DSC plot for the first 30 minutes. The signal reached a plateau in 125 minutes and no further reactions were observed. 


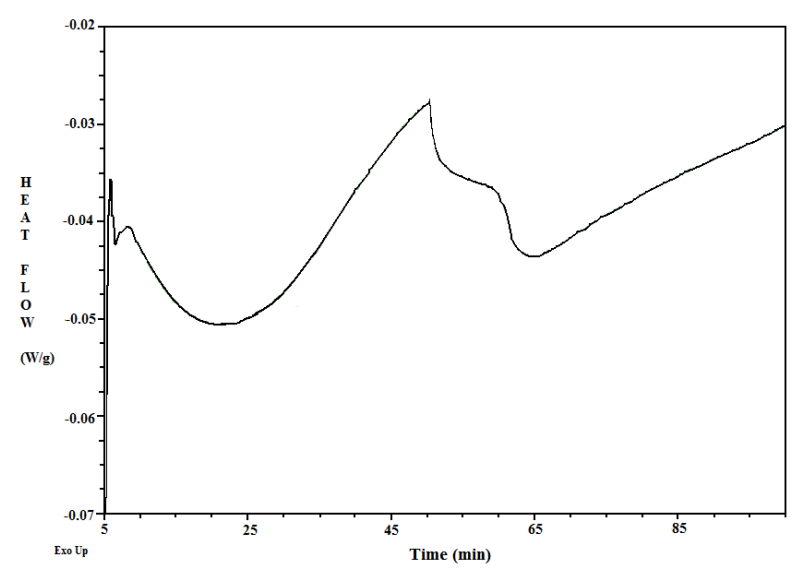

Fig 8a Isothermal Test Held at $25^{\circ} \mathrm{C}$

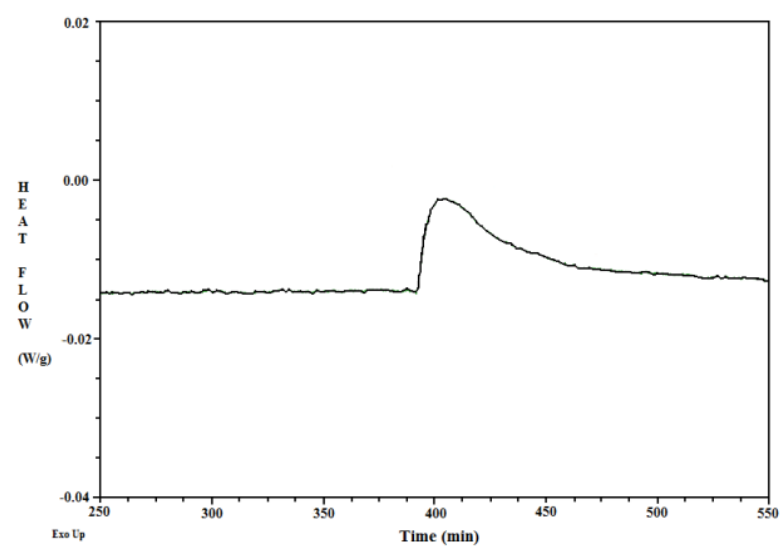

Fig 8b Ramped up to $85^{\circ} \mathrm{C}$ for $12 \mathrm{hrs}$.

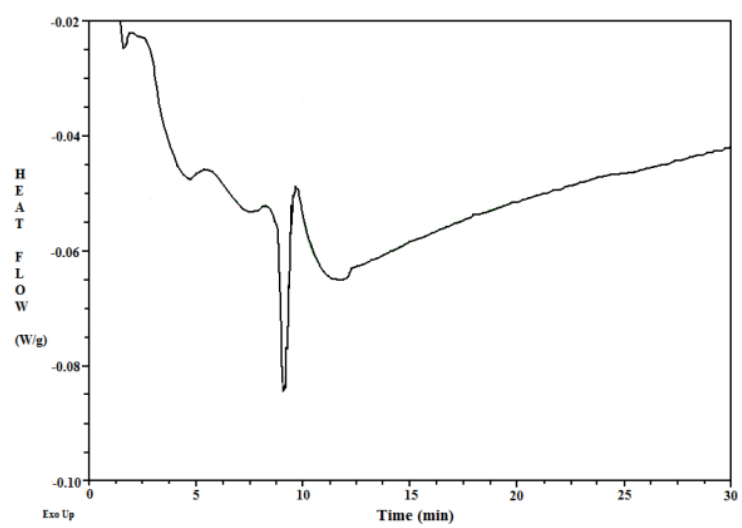

Fig 8c Ramped to $-20^{\circ} \mathrm{C}$ then to $65^{\circ} \mathrm{C}$ and held for 10 hours

\section{SAMPLE COST ANALYSIS}

\subsection{Initial Findings}

A cost analysis concluded an average price of production of alkali-activated slag (AAS) with NYAD G to be $\$ 900$ per cubic meter. Compared to the cost of a $34.47 \mathrm{MPa}(5000$ psi) concrete, which was estimated to be $\$ 138$ per cubic meter, this formulation is about 6.4 times more expensive to produce than concrete. For the formulations with wollastocoat, the total price varied from approximately $\$ 1000$ to $\$ 1300$ per cubic meter depending on the loading.
All costs were based on market prices for materials found in Western New York.

This analysis suggests that to make an economically competitive product based on alkali activation, the use of aggregates to increase overall volume needs to be explored.

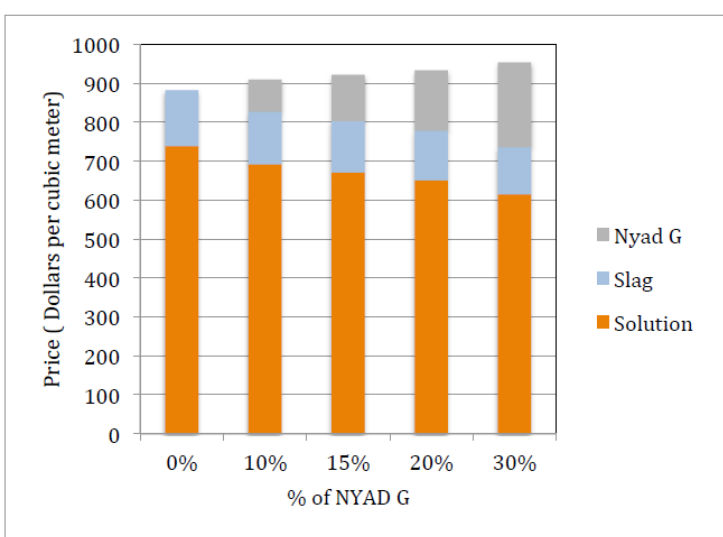

Fig 9 Cost breakdown per cubic meter for formulations with NYAD G

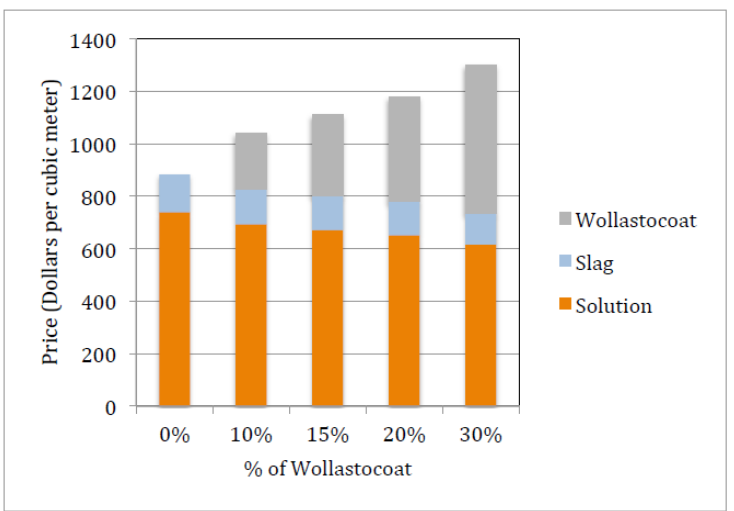

Fig 10 Cost breakdown per cubic meter for formulations with Wollastocoat

\subsection{Cost Reduction Experimentation}

For this experiment, the formulation with $10 \%$ NYAD G was used as well as mine tailings provided by NYCO Minerals in the same volumetric proportion of GGBFS. All samples were prepared and cured as previously presented. Figures 11 and 12 present the results for compressive strength and setting time, respectively. The samples with mining tails had an initial compressive strength of 51.7 MPa and lost only $18 \%$ in 28 days.

The setting time showed an unexpected behavior. When mine tailings were used, the setting time increased by a factor of 2, something that we haven't observed before. 


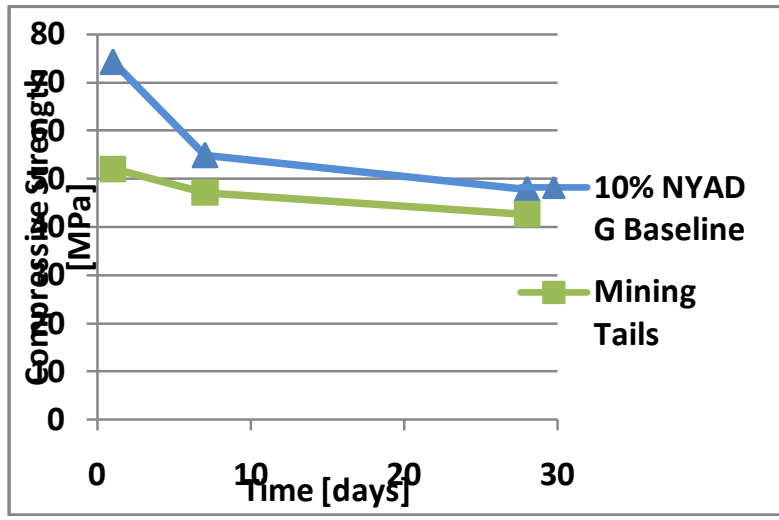

Fig 11 Compressive Strength Comparison over a 28 Day Period

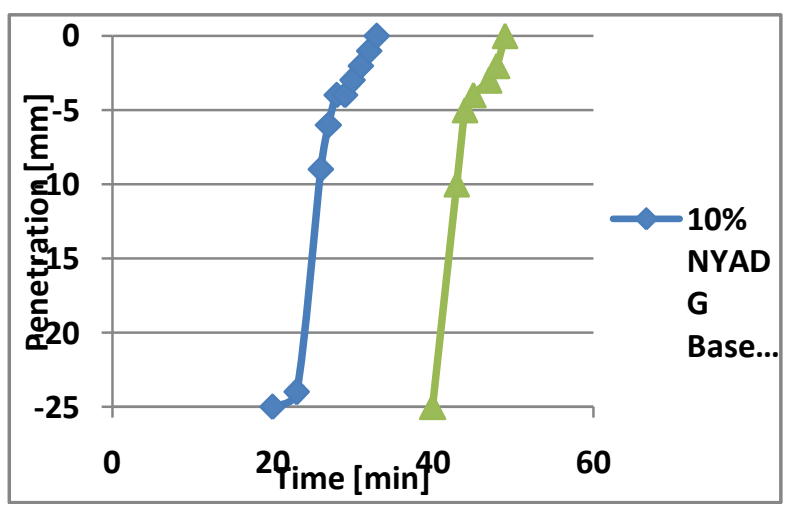

Fig 12 Setting Time Comparison

\section{CONCLUSIONS}

The curing conditions have a significant impact on the compressive strength of alkali-activated slag. Curing at $85^{\circ} \mathrm{C}$, as many researchers report, has the effect of increasing the 1 day compressive strength, but, we found, also causes a rapid decrease in strength during the first 7 days. Under this condition, the inside temperature can pass $100^{\circ} \mathrm{C}$ causing water evaporation and the large cracks on the surface. Samples cured at room temperature reached a 7 day compressive strength of $44.8 \mathrm{MPa}$ and they remained stable after 28 days. Based on these observations, it is suggested to cure the samples at temperatures in the range of room temperature to $50^{\circ} \mathrm{C}$.

Differential Scanning Calorimetry showed a series of endothermic and exothermic reactions during the first 15 minutes. This suggests the formation of an unstable gel, which melts and later reconfigures into a more stable phase as indicated by the larger exothermic peak. We found a correlation between this exothermic peak and the setting time, both start at approximately 25 minutes.

Based on 28 day compressive strength and setting time curves, we found that the optimum loading of NYAD G is in the $15 \%-20 \%$ range. Compressive strength for samples in this range is approximately $55.1 \mathrm{MPa}$, which is a $60 \%$ increase with respect to samples without NYAD G. The setting time in both cases starts at approximately 20 minutes. In the case of samples with wollastocoat, similar results were obtained, but the optimal loading is in the $20 \%$ -
$30 \%$ range. Setting time curves show that in order to see the retarding effect of wollastocoat in the setting time, a higher loading must be used.

The cost analysis revealed that the AAS is about 6.4 times more expensive than concrete. The estimated cost for AAS without wollastonite is $\$ 880$ per cubic meter. For the suggested optimal NYAD G loading, the estimated total price increased approximately $4 \%$ and for the suggested optimal loading with wollastocoat the total price increased from $25 \%$ to $32 \%$. The main contributing factor of the cost is the alkaline solution, which represents more than $50 \%$ of the total cost.

The cost of AAS is significantly higher than concrete based on Portland cement. For this reason, is necessary to find specialized applications to justify its cost. It was suggested that due to the combined effects of high early compressive strength, fast setting, and thermal stability of AAS with wollastonite, a potential niche of application is the stabilization of civil infrastructure after natural disasters. In cases like this, quick restoration of roads, bridges and buildings is necessary and the cost will be justified.

Control of setting time is an outstanding problem in this field. The last set of experiments suggested that this can be accomplished by a careful selection of aggregates. The use of NYCO mine tailings doubled the setting time, yielded samples with an average compressive strength of $41.3 \mathrm{MPa}$, and can significantly cut down the total cost.

\section{ACKNOWLEDGEMENTS}

We want to express our gratitude to NYCO Minerals, especially to Mr. Sal LaRosa, for providing financial and material support for this project. Our gratitude is also extended to Mr. Thomas A. Leasure at Manitou Concrete for providing us with the slag used in this study. Finally we express our gratitude to the Kate Gleason College of Engineering for providing extra funding for this project.

\section{REFERENCES}

[1]. Davidovits, J. (2008). Geopolymer Chemistry \& Applications. Institut Geopolymére.

[2]. Davidovits, J. (1991). Geopolymers, Inorganic Polymeric New Materials. Journal of Thermal Analysis, 37, 1633-1656.

[3]. Dombrowski, K., Buchwald, A., \& Weil, M. (2007). The Influence of Calcium Content on the Structure and Thermal Performance of Fly Ash Geopolymers. Journal of Materials Science, 42 (9), 3033-3043.

[4]. Duxson, P., Fernandez-Jimenez, A., \& Provis, J. L. (2007). Geopolymer Technology: The Current State of the Art. Journal of Materials Science (42), 2917-2933.

[5]. EPA. (2003). Industrial Waste Management, A Guide to Best Practices.

[6]. EPA. (2009). Using Recycled Materials in Roadways.

[7]. Fernandez-Jimenez A., Palomo J. G., \& Puertas, F. (1999). Alkali-Activated Slag Mortars Mechanical 
Strength Behavior. Cement and Concrete Research, 29, 1313-1321.

[8]. Harditjo, D., \& Rangan, B. V. (2005). Development and Properties of Low Calcium Fly Ash Based Geopolymer Concrete. Research Report GC1, Curtin University of Technology, Faculty of Engineering.

[9]. NYCO Minerals. (2012). Wollastonite. One mineral, a World of Applications.

[10]. Palomo, A., Grutzeck, M. W., \& Blanco, M. T. (1999). Alkali-Activated Fly Ashes, A Cement for the Future. Cement and Concrete Research, 29, 1323-1329.

[11]. Provis, J. L., \& Van Deventer, J. S. (2009). Geopolymers - Structure, Processing, Properties and

Industrial Applications. Woodhead Publishing.

[12]. Purdon, A. O. (1940). The Action of Alkalis on Blast Furnace Slag. Journal of the Society of Chemical Industry, 59, 191-202.

[13]. Richardson, I. G., Brough, A. R., Groves, G. W., \& Dobson, C. M. (1994). The Characterization of

Hardened Alkali-Activated Blast Furnace Slag Pastes and the Nature of the Calcium Silicate Hydrate Phase. Cement and Concrete Research, 24 (5), 813-829.

[14]. Shi, C., Krivenko P.V., \& Roy D.(2006). AlkaliActivated Cements and Concretes. Taylor \& Francis.

[15]. Shilling, P. J., Butler, L. G., Amitava, R., \& Harvill, E. C. (1994). $29 \mathrm{Si}$ and 27 AlMAS-NMR of $\mathrm{NaOH}$ Activated Blast-Furnace Slag. Journal of the American Ceramic Society, 77 (91), 2363-2368.

[16]. Silva, F. J., \& Thaumaturgo, C. (2002). Fiber Reinforced and Fracture Response in Geopolymeric Mortars. Fatigue and Fracture Engineering Materials \& Structures, 26, 167-172.

[17]. Song, S., Sohn, D., Jennings, H. M., \& Mason, T. O. (2000). Hydration of Alkali-Activated Ground

Granulated Blast Furnace Slag. Journal of Materials Science, 35, 249-257.

[18]. Van Jaarseveld, J.G.S., Van Deventer, J. S. J, \& Lukey, G. C. (2003). The Characterization of Source

Materials in Fly Ash Geopolymers. Materials Letters, 57, 1272-1280.

[19]. Van Oss, H. G. (2012). Cement. United States Geological Survey, Minerals Commodity Summaries.

[20] Van Oss, H. G. (2010). Slag- Iron and Steel. United States Geological Survey Minerals Yearbook

\section{BIOGRAPHIES}

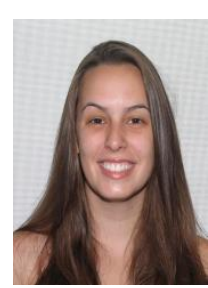

Ashley M. Waldron is a $5^{\text {th }}$ year Mechanical Engineering student at Rochester Institute of Technology in NY. She has been working with alkali activated materials since the summer of 2013 using various forms of wollastonite to improve mechanical properties and reduce cost.

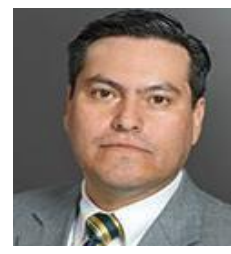

Benjamin Varela is an Associate Professor in the Mechanical Engineering Department at the Rochester Institute of Technology, NY 